
PARENTS AFTER DEATH OF AN INFANT, R1chard L. Schre1ner, Edwin L. Gresham (Spon. by Morris Green), Ind1ana University School of Medicine, Indiana University Hospitals, Department of Pediatrics, Indianapolis.

In many newborn intensive care units (NBICU) patients are referred from great distances, and personal interviews after the death of an infant are not feasible. Therefore, we have evaluated the effect of a single phone call 8 days after the death of an Infant in preventing psychopathological reactions. Eleven parents who had received no formal contact from the NBICU after the death of the infant were interviewed at the hospital at 825 weeks (mean 18). Eleven other parents whose Infants died on the same NBICU were called 3-15 days (mean 8) after the death. The call lasted 25 minutes (range 15-35). These parents were also interviewed at the hospital at 11-18 weeks (mean 13) after the death. Nine different problems were investigated and graded on a scale of $0-3$ for severity. Parents who received a call had a total average score of $2.3 \pm 1.8$ compared to $8.8 \pm 2.3$ for those not called. Two of 11 families who were contacted by phone had 2 significant problems compared to 36 moderate or major difficulties in all 11 families who had not been called. The important problems that persisted in families who had not recelved a call included depression, guilt feelings, questions of heredity, problems involving the extended family and concerns about the cause of death. This study shows that a 25 -minute phone call 8 days after the death of an infant has beneficial effects in alleviating emotional problems in the parents.
68 BRAZELTON BEHAVIOR TESTING IN THE HIGH RISK NEWBORN E1sa Sell and Suzy Polsson (Spon. by Grant Morrow)

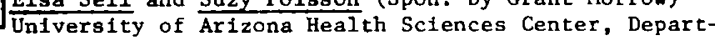
ment of Pedfatrics, Tucson

The Brazelton Scale was administered to $204 \mathrm{~h} 1 \mathrm{gh}$ risk infants; 366 tests were given. $88 \%$ were $<2500 \mathrm{~g}$ and $90 \%$ were $<36$ weeks gestation. $42 \%$ had assisted ventilation, and $19 \%$ were small for gestational age. Gestational age at test time was $35-43$ weeks in 92\%. Deviant reflexes (scored as 0,1 or 3 except for passive movements) were: crawling (20\%), standing (39\%), placing (23\%) Moro (27\%), walking (79\%), and passive movements of arms (77\%) $\delta$ 1egs (82\%). Mean scores on decrement and orientation items were response decrement to light 5.9 inanimate visual 5.5 response decrement to rattle 6.6 inanimate auditory 5.9 \begin{tabular}{llll} 
response decrement to bell & 5.4 & animate visual & 5.4 \\
response decrement to pin prick & 5.5 & animate auditory & 6.5 \\
\hline
\end{tabular}

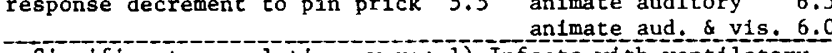
1) Infants with ventilatory support were less able to self quiet or to be consoled; 2) The longer the ventilatory support the poorer the self quieting, consolability and response to animate stimuli, but the better the use of postural changes to self quiet; 3) Gestational age a birth and/or test time influenced dominant states, alertness, consolability, pull to sit, activity, and response to inanimate auditory stimulus.

Conclusion: gestational age and perinatal events influence high risk infant responses to the Brazelton test so that their behavior is not accurately described by term newborn standards.

69 TEONATAL BEHAVLORAI ASSESSMENT AND PSYCH NEONATAL BEHAVIORAL ASSESSMENT AND PSYCHOLOGICAL OUT-
COME AT 1 YEAR IN HIGH RISK INFANTS. Elsa Sell, Suzy Poisson, and Bob Rentfrow. (Spon. by Grant Morrow) Arizona Health Sciences Center, Dept. Pediatrics \& University of Arizona, Dept. of Special Education, Tucson.

33 infants requiring ICU nursery care had Brazelton Behavioral Testing prior to discharge and were followed for 1 year. At birth $91 \%$ were $<2500 \mathrm{~g}$. and 37 wks. gestation; $61 \%$ were caucasian, $30 \%$ Mexican-American; $64 \%$ had birth asphyxia; $15 \%$ were SGA; $58 \%$ had IRDS with $70 \%$ of those ventilated. The Brazelton Test was performed at 35-42 weeks in $88 \%$. At 1 year the Bayley test was administered. The results were corrected for gestational age and the percent achieving each score are below:

\begin{tabular}{lcc} 
Bayley Score & Motor & Menta1 \\
\cline { 2 - 3 } & \multicolumn{1}{c}{$5 \%$} & $5 \%$ \\
$116-132$ & $40 \%$ & $21 \%$ \\
$85-115$ & $44 \%$ & $42 \%$ \\
$68-84$ & $12 \%$ & $16 \%$ \\
-68 & & $16 \%$
\end{tabular}

Complete tests were not achieved in ail children because of fat gue or failure to cooperate. Significant correlations found were: 1) SGA babies did more poorly on fine motor tasks, 2) Infants who had better self organfzation on the Brazelton had better scores on gross motor tasks, and 3) Infants with better passive resistance to arm movement on the Brazelton scored better on both motor and mental parts of the Bayley.

Conclusion: Two items in the Brazelton test correlated with good performance on the Bayley test in high risk infants. Seetha Shankaran and Lee Ann Del Bianco (Spon. by RonUniv. and the Children's Hospital of Michigan, Detroit. A group for parents of high-risk newborns on a NNICU was organ ized in June 77 . Core-members establishing the group were the neo natology staff including nurse clinician, social worker and clergyman. Parents of infants previously discharged from the unit also participated. Goals were to provide information, to encourage parents to express their feelings and to facilitate munication. Evening meetings were scheduled bi-monthly on the unit. Parents were encouraged to attend while visiting their infants; three core-members were always present. 57 parents (of 34 infants) participated over the six-month period, up to 11 parents attending at a time. Discussions were unstructured; core-member listened and facilitated conversation only when necessary.

Parents shared feelings, recounted pregnancy and birth experi ences, and felt less alone. Few questions arose about specific heonatal illnesses. Recurrent topics were lapses in communication and concern over new resident rotations. Mothers requested transfer from obstetrical units following the transport of their sick newborns.

This preliminary evaluation resulted in specific changes on the NNICU including a "crying room", baby-sitting for sibs, parent pooklet explaining terminology and reduction in parking fees for fhronic patients. This program does not replace parent communication on an individual level. In the high-stress situation of neohatal care, it provides parents with added support, and the NNICU,

71 THE EXPANDED FETAL ALCOHOL SYNDROME (EFAS)-BEHAVIORAL IGENCE. Sally E. Shaywitz, Donald J. Cohen, Bennett . Shaywitz, Dept. of Ped., Yale Un. Sch. of Med., New Haven. Prenatal exposure to ethanol may result in a profound morpho$\operatorname{logic}$ disorder, FAS. We now report that maternal alcoholism may be central to the pathogenesis of those subtle yet more freque $1 y$ encountered abnormalities of attention, behavior, activity and learning that comprise the minimal brain dysfunction symptom complex. The 9 boys and 2 girls, ages $9-18$ years referred to the YNHH Learning Disorders Unit were born to heavy drinking mothers. They exhibited many of the features of FAS: prenatal growth defiency ( $70 \%$ SFGA, median b.w. $2270 \mathrm{~g}$ ), postnatal growth deficits in $73 \%$, and microcephaly in $63 \%$. Facial stigmata were noted in $73 \%$ and mild limb abnormalities in $50 \%$. Each had average intelligence (WISC) with median Full Scale I.Q. 96, (range 86-113), Verbal I.Q. 101, (82-123) and Performance I.Q. 94, $(81-120)$. Poorest performance on psychometric testing (Coding, Arithmetic, Digit Span, Information) reflected deficits in attention, concentration, memory and learning common to all. Each manifest hyperactivity during early school years and impulsivity and fidgetiness which remained with them as adolescents. All exhibited school difficulties requiring retention of at least one year and special education services. We suggest that the pattern of hyperactivity, attentional deficits and school learning difficulties despite average intelligence associated with subtle morphologic anomalies may represent a symptom complex th more accurately reflects the full and perhaps often overlooked

\section{THE PROGNOSIS OF NONORGANIC ABDOMINAL PAIN IN}

72 CHILDREN. Gunnar B. Stickler and Dennis B. Murphy. Mayo $\mathrm{Clinic}$, Department of Pediatrics, Rochester, MN In order to determine prognosis in children in whom the diag nosis of "functional" or psychosomatic abdominal pain had been
made, a questionnaire was sent to parents of 170 children in whom the diagnosis had been made at least $5 \mathrm{yr}$ previously. Responses were obtained for 161 patients (pt) $(94.7 \%$ ). In this group (100 girls, 61 boys), all symptoms disappeared in 92 pt (57.1\%) within a few weeks after diagnosis and reassurance by the examining physician. In $31 \mathrm{pt}(19.3 \%)$, symptoms subsided from 1 to $9 \mathrm{yr}$ (mean 3.2 yr) after diagnosis. Symptoms remained unchanged in 15 pt $(9.3 \%)$ and became worse in $7(4.3 \%)$. Sixteen responders failed to con subjected to surgical procedures elsewhere; these included appendectomy, removal of "ovarian cysts," tonsiliectomy and adenoidectomy, and laminectomy. Six pt thought tonsillectomy and adenoidectomy, and laminect, but 12 pt either that they had been helped by these procedures, but 12 pt either continued to have abdominal pain or had multiple psychosomatic complaints. In $3 \mathrm{pt}$, the diagnosis of Crohn's disease ultimatel cause of organic bowel disease was detected. In $1 \mathrm{pt}$, anorexia hervosa was later diagnosed. We conclude that organic disease is seldom overlooked in pt considered to have functional or psychosomatic abdominal pain. The symptoms eventually disappeared chosomatic abdominal pain. The symptoms eventualsistent symptoms in approximately $75 \%$ of these $\mathrm{pt}$; those with persistent symptons or the development of other psychosomatic complaints. 